\title{
HIDRATAÇÃO DE TECIDOS DE RAÍZES DE MANDIOCA (Manihot esculenta Crantz.) E GELATINIZAÇÃo DO AMIDO DURANTE A COCÇÃO'
}

\author{
Soraya S. BUTARELO², Adelaide BELEIA ${ }^{2, *}$, Inês Cristina de Batista FONSECA³, Kelly Cristina ITO ${ }^{2}$
}

\section{RESUMO}

Durante a cocção da mandioca ocorrem modificações físicas e químicas nos tecidos e a textura final é importante para a aceitabilidade e o consumo de mandiocas. A cocção a $80^{\circ}$ e em água em ebulição de duas cultivares, aos 12 e 25 meses após o plantio, foi acompanhada determinando-se o ganho de peso (hidratação) e o grau de gelatinização das amostras. Gelatinização foi determinada por colorimetria com iodo após dissolução em álcali das amostras cozidas por diferentes períodos de tempo. $\mathrm{A} 80^{\circ} \mathrm{C}$ a hidratação e a gelatinização não se completaram, o que ocorreu com a cocção em água em ebulição. O grau de hidratação foi diferente entre cultivares e entre amostras de 12 e 25 meses de plantio e pode ser descrito matematicamente por modelo de ordem zero. Amostras colhidas 12 meses após ao plantio hidrataram mais rápido que aos 25 meses e a cultivar IAPAR-19 Pioneira hidratou mais rápido que a cultivar Catarina Amarela. Quanto mais rápida a hidratação mais rápido o cozimento e quanto maior a hidratação maior o rendimento em produto cozido.

Palavras-chave: mandioca; Manihot esculenta C.; tempo de cocção; gelatinização.

\section{SUMMARY}

HYDRATION OF CASSAVA TISSUES AND STARCH GELATINIZATION DURING THE COOKING PROCESS. Cooking of cassava root tissues causes both physical and chemical modifications and the final texture of the product is important for the acceptability and consumption of the food. Cooking tissue samples at $80^{\circ}$ and in boiling water from two cultivars, harvested 12 and 25 months after planting date, was accompanied by determinig weight gain and starch gelatinization of the samples. Starch gelatinization was determined by colorimetry with iodine after solubilization in alkali of samples cooked for different period of times. At $80^{\circ} \mathrm{C}$ neither hydration or gelatinization were complete, which occurred at in boiling water. Hydration was different between cultivars and harvesting ages and could be described by a zero order mathematical model. Samples harvested 12 months after planting date hydrated faster than the ones harvested after 25 months and IAPAR-19 Pioneira hydrated faster than Catarina Amarela. The faster the rate of hydration the faster the samples cooked and higher the final cooked weight.

Keywords: cassava; Manihot esculenta C.; cooking time; gelatinization.

\section{1 - INTRODUÇÃO}

A mandioca é um dos vegetais mais cultivados no mundo sendo o Brasil um dos principais países produtores. As raízes tuberosas das mandiocas bravas são usadas como matéria-prima industrial para a produção de fécula e farinha, mas as mandiocas mansas, que possuem teor de cianeto inferior a 100ppm na polpa crua, são consumidas como vegetal fresco sob várias formulações, após tratamento hidrotérmico [5, 12]. Atualmente mandioca para uso culinário é encontrada minimamente processada, refrigerada ou congelada, e também na forma pré-cozida, facilitando o preparo e o consumo.

Órgãos vegetais que armazenam substâncias são formados por tecidos constituídos de células que contem o material de reserva e por membranas celulares ricas em carboidratos. Raízes de mandioca armazenam amido e após a cocção em água resultam em produtos com características texturais e estruturais próprias mas importantes para a aceitabilidade pelo consumidor. $\mathrm{O}$ amido é o constituinte mais abundante das raízes de mandioca e durante o processamento hidrotérmico sofre modificações que estão relacionadas com a gelati-

\footnotetext{
Recebido para publicação em 09/04/2001. Aceito para publicação em 28/05/2004 (000607).

2. Departamento de Tecnologia de Alimentos e Medicamentos - Universidade Estadual de Londrina. Caixa Postal 6001, CEP: 86051-970, Londrina-PR. E-mail: beleia@uel.br

3. Departamento de Agronomia - Universidade Estadual de Londrina. * A quem a correspondência deve ser enviada.
}

nização e propriedades associadas, como absorção de água e aumento do volume dos grânulos, que afetam os tecidos celulares, tendo provavelmente função importante nas características finais do produto cozido.

A qualidade de mandioca cozida tem sido estudada por vários autores $[5,6,7,11,12,13]$. EGGLESTON \& ASIEDU [7] determinaram a compressibilidade de cubos de vários cultivares de mandioca cozidos por 20min, encontrando correlação positiva entre a textura final e o conteúdo em matéria seca e a adesão intercelular. SAFO-KANTANKA \& OWUSU-NIPAH [13] classificaram empiricamente a elasticidade e uniformidade da massa de mandioca cozida em farinhenta (desejável) e vítrea (indesejável). CARVALHO et al. [5] avaliaram 16 cultivares de mandiocas de mesa que foram selecionadas para produção e comercialização a partir de dados em rendimento, tempo de cocção, presença de fibras e consistência da polpa (plástica ou pegajosa). LORENZI [11] avaliou tempo de cozimento e qualidade da massa e concluiu que quanto mais rápido o cozimento, geralmente, melhor era a qualidade da massa e que tempo de cozimento era influenciado pela idade das raízes. CEREDA et al. [6] avaliaram a qualidade da cultivar IAPAR-19 Pioneira que foi considerada adequada para consumo mesmo aos 24 meses após o plantio, ou um ano após o tempo usual de colheita.

Maximizar qualidade e minimizar perdas durante o tratamento hidrotérmico requer o conhecimento prévio do comportamento do material durante a cocção. A industrialização de alimentos requer dados sobre rendi- 
mento de produtos para detectar vantagens econômicas na escolha das matérias-primas. O objetivo deste trabalho foi modelar matematicamente o processo de hidratação durante a cocção de duas cultivares de mandioca usadas para fins culinários, em dois estádios de maturação. O grau de gelatinização do amido em algumas etapas da hidratação foi determinado.

\section{2 - MATERIAL E MÉTODOS}

\section{1 - Matéria-prima}

A mandioca fresca foi fornecida pelo sítio Mirantro, situado na zona rural de Londrina, PR, a $23^{\circ} 19^{\prime}$ de latitude sul e $51^{\circ} 12^{\prime}$ de longitude oeste. O município de Londrina tem altitude média de $575 \mathrm{~m}$. As cultivares Catarina Amarela e IAPAR-19 Pioneira, cultivadas na região para consumo como vegetal fresco ou mandioca de mesa, foram plantadas em solo classificado como terra roxa estruturada eutrófica. O terreno foi capinado quando necessário, sendo este o único trato cultural durante o desenvolvimento e o crescimento das plantas. Doze e 25 meses após o plantio (agosto de 1996 e outubro de 1997), as raízes foram colhidas (setembro e outubro de 1998) e trazidas para o laboratório. Houve colheitas diárias até que todos os experimentos foram realizados, inclusive os testes preliminares.

\section{2 - Preparo das amostras}

As raízes foram lavadas, descascadas, fatiadas transversalmente ao eixo longo e as fatias $(2 \mathrm{~cm}$ de altura) foram cortadas em cubos com $2 \mathrm{~cm}$ de lado $\left(8 \mathrm{~cm}^{3}\right)$. Após o corte cada cubo foi pesado e submetido, ao acaso, a uma determinada combinação de tempo e temperatura de cocção em $200 \mathrm{~mL}$ de água. O cubo era envolto em gaze, mergulhado em água na temperatura do tratamento e a contagem do tempo iniciava no momento da imersão da amostra. Após o tratamento o cubo era lavado, disposto sobre papel toalha, seco em estufa com circulação forçada de ar a $35^{\circ} \mathrm{C}$, para a determinação do grau de gelatinização ou pesado para a determinação do grau de hidratação da amostra (ganho de peso).

Em testes preliminares foi determinado o tempo necessário para atingir a gelatinização máxima a $80^{\circ} \mathrm{C}$, usando o teste descrito para grau de gelatinização [3, 4]. Guando a cocção foi realizada em água em ebulição o ponto final foi determinado por meio empírico, através de análise visual (cor e aparência dos tecidos) e textural (penetração de dentes de garfo). Nos tratamentos experimentais o tempo predeterminado de cocção foi subdividido em 8 períodos eqüidistantes para determinar a hidratação. A gelatinização foi determinada em 4 pontos, o inicial, um médio e os dois últimos.

\section{3 - Composição química, hidratação e grau de ge- latinização}

A umidade foi determinada em estufa a vácuo a $70^{\circ} \mathrm{C}$, proteína pelo método de micro-Kjeldahl, lipídios por extração em Soxhlet e cinzas por calcinação em mufla a $550^{\circ} \mathrm{C}$ [1]. Amido foi determinado após hidrólise ácida e titulação com reagente de Fehling [10]. O material não quantificado foi obtido por diferença e denominado carboidratos não amido (CNA) na Tabela 1.

A hidratação, calculada em porcentagem de ganho de peso em relação ao peso inicial, sem considerar os sólidos e os solúveis perdidos na água de cocção, foi obtida por gravimetria logo após a cocção e resfriamento da amostra. O grau de gelatinização foi determinado por colorimetria do complexo azul formado com iodo e amilose após solubilização da amostra em soluções de $\mathrm{KOH} 0,06 \mathrm{M}$ e $0,4 \mathrm{M}$ por $15 \mathrm{~min}$. A razão entre as absorções das duas solubilizações nas diferentes concentrações de KOH identifica o grau de gelatinização [3, 4]. A curva padrão para grau de gelatinização foi preparada com diferentes proporções de amostras cruas, secas e moídas e amostras gelatinizadas em autoclave por $15 \mathrm{~min}$, secas e moídas, consideradas 100\% gelatinizadas.

\section{4 - Delineamento experimental e tratamento dos dados}

O delineamento experimental foi em esquema fatorial, com duas cultivares (IAPAR-19 Pioneira e Catarina Amarela), duas épocas de colheita (12 e 25 meses) e duas temperaturas, 80 e $98^{\circ} \mathrm{C}$ (temperatura da água em ebulição na altitude de Londrina). Foram realizadas duas cocções (repetições) em cada temperatura. Foi feita análise de covariância, sendo os tempos de cocção considerados como covariáveis [15]. As comparações de médias foram feitas com o teste de Tukey, quando apropriado [14, 15].

O ganho percentual de peso foi matematicamente representado por modelo de ordem zero para cada cultivar, maturidade e temperatura e os coeficientes de velocidade calculados por regressão [15].

\section{3 - RESULTADOS E DISCUSSÃO}

\section{1 - Composição química}

A composição da matéria-prima é característica, com grande predominância de amido e outros carboidratos sobre os outros componentes (Tabela 1). O teor de amido variou entre 83,7 para IAPAR-19 Pioneira aos 25 meses e 92,4g/100g, em base seca, para Catarina Amarela aos 12 meses. As raízes de 25 meses tinham menor quantidade de amido, em média $86,1 \mathrm{~g} / 100 \mathrm{~g}$, que as raízes mais jovens, em média 92,3g/100g. A quantidade de carboidratos não amido (CNA), composta desde monossacarídeos livres a polímeros como pectina, celulose e hemicelulose, aumentou com a idade das raízes, variando de 3,3 para IAPAR-19 Pioneira 12 meses a 11,9g/100g para IAPAR-19 Pioneira 25 meses.

O teor de proteína variou entre 1,06 e 1,38g/100g de matéria seca, tendo IAPAR-19 Pioneira apresentado os valores mais altos. A quantidade de cinzas permaneceu praticamente constante sendo em média $2,35 \mathrm{~g} / 100 \mathrm{~g}$. Lipídios aparentemente aumentaram com o tempo de plantio mas o valor total permaneceu bai- 
xo. A composição química da cultivar IAPAR-19 Pioneira foi apresentada por CEREDA et al. [6] que encontrou $83,5 \%$ de amido e $5 \%$ de proteína aos 9 meses e $89,9 \%$ de amido e 1,9\% de proteína aos 25 meses. CNA calculados por diferença, da tabela de composição apresentada no trabalho de CEREDA et al. [6], foi de 7,3\% aos 9 meses e de 5,3\% aos 24 meses.

TABELA 1. Composição química de mandiocas descascadas das cultivares IAPAR-19 Pioneira e Catarina Amarela, aos 12 e 25 meses após o plantio (base seca).

\begin{tabular}{l|cccc}
\hline \multirow{2}{*}{ Variáveis } & \multicolumn{2}{|c|}{ IAPAR-19 Pioneira } & \multicolumn{2}{c}{ Catarina Amarela } \\
\cline { 2 - 5 } & 12 meses & 25 meses & 12 meses & 25 meses \\
\hline Amido & $92,3 \pm 0,5$ & $83,8 \pm 0,4$ & $92,4 \pm 1,0$ & $88,5 \pm 1,3$ \\
Proteína bruta & $1,38 \pm 0,002$ & $1,37 \pm 0,004$ & $1,07 \pm 0,059$ & $1,06 \pm 0,009$ \\
Cinzas & $2,54 \pm 0,03$ & $2,44 \pm 0,02$ & $2,12 \pm 0,2$ & $2,33 \pm 0,04$ \\
Lipídios & $0,43 \pm 0,01$ & $0,53 \pm 0,3$ & $0,52 \pm 0,03$ & $0,61 \pm 0,01$ \\
CNA & 3,35 & 11,86 & 3,89 & 7,50 \\
\hline
\end{tabular}

CNA carboidratos não amido, determinados por diferença.

\section{2 - Hidratação de tecidos e gelatinização do amido}

O ganho de peso médio durante a cocção variou com a temperatura, cultivares e idade das raízes (Tabelas 2 $e$ 3). Não houve interação significativa entre os fatores estudados pela análise de covariância, mas os fatores principais foram significativos e estudados isoladamente. A cultivar IAPAR-19 Pioneira teve ganho médio de peso de $14,5 \pm 8,2 \%$ considerando as duas épocas de colheita e temperaturas de cocção, diferente no nível de $5 \%$ de probabilidade, da média de $5,1 \pm 3,6 \%$ para Catarina Amarela. Ganho de peso das raízes de 12 meses, média das duas cultivares nas duas temperaturas de cocção de $10,8 \pm 8,6 \%$ foi diferente no nível de $5 \%$ de probabilidade, de $8,8 \pm 6,8 \%$ aos 25 meses de plantio. O ganho de peso médio a $80^{\circ} \mathrm{C}$, das duas cultivares, $8,67 \pm 7,06 \%$, foi diferente de $11,02 \pm 8,57 \%$, cocção em água em ebulição. Os desvios padrão das médias foram altos devido à variação do material e aos ganhos de pesos diferentes nas diferentes temperaturas e tempos de cozimentos. Menor tempo de cocção correspondeu a maior ganho de peso.

Os principais componentes da mandioca, os carboidratos, são classificados como hidrocolóides e são substâncias capazes de reter água durante o processo de cocção. Durante o tratamento hidrotérmico a água é absorvida pelo amido e outros carboidratos, como fibras solúveis e insolúveis das paredes celulares e lamela média, causando aumento do volume celular e a separação de células. No processo de cocção de batatas, as células aumentaram em média 138\% de diâmetro, processo descrito por modelo matemático de primeira ordem [9]. EGGLESTON \& ASIEDU [7] encontraram valores de hidratação que variaram entre 0.04 e 11,52\% para oito variedades de mandiocas, colhidas 16 meses após o plantio, mas o tempo de cocção foi igual para todas as amostras e fixado em 20min.
A gelatinização do amido depende da temperatura e da quantidade de água disponível para a transição de fase e provavelmente, quanto mais fácil a hidratação mais rápida a gelatinização [2]. A $80^{\circ} \mathrm{C}$ os processos tanto de hidratação quanto de gelatinização não atingiram valores tão altos quanto os obtidos em água em ebulição, independente do tempo de cocção, para as duas cultivares e maturidades, embora a temperatura usada fosse superior a temperatura de gelatinização de amidos isolados de mandioca [16]. Amido contido nos tecidos da cultivar IAPAR-19 Pioneira, 12 meses, teve $85,3 \%$ de gelatinização com $25,4 \%$ de hidratação a $80^{\circ} \mathrm{C}$ e $85.1 \%$ de gelatinização com $12,5 \%$ de hidratação à temperatura da água em ebulição.

A água de hidratação é adicionada à quantidade natural de água presente nos tecidos, em média nas mandiocas $65 \%$, que é teoricamente suficiente para a completa gelatinização de grânulos de amidos isolados. Segundo BILIADERIS [2] amidos isolados apresentaram uma única endoterma de gelatinização no calorímetro diferencial de varredura quando aquecidos em presença de $60 \%$ de água. A própria organização estrutural e composição química dos tecidos, com uma determinada densidade e a existência de paredes celulares pode retardar a difusão de água para o interior da amostra o que não ocorre com grânulos isolados. Amido em grãos de arroz não gelatinizou completamente quando cozidos a $70^{\circ}$ ou $80^{\circ} \mathrm{C}$, embora grânulos de amido isolados de arroz gelatinizem em uma faixa de temperatura entre $65^{\circ}$ e $73^{\circ} \mathrm{C}[2,3]$.

Amido nos tecidos da cultivar IAPAR-19 Pioneira atingiu o maior grau de gelatinização $(85,3 \%)$ a $80^{\circ} \mathrm{C}$ após 92min para amostras de 12 meses e 74,7\% após 160min para amostras de 25 meses, enquanto que em água em ebulição os tempos foram de 12 e 32 minutos para 98 e $97,5 \%$ de gelatinização. A temperatura de $90^{\circ} \mathrm{C}$ batatas necessitaram de $48 \mathrm{~min}$ para cozinhar enquanto que a $100^{\circ} \mathrm{C}$ levaram $12 \mathrm{~min}$, com tempo de cocção determinado por teste de textura [8].

Os valores de hidratação foram menores para a cultivar Catarina Amarela nas duas temperaturas e nas duas épocas de colheita, quando comparado à IAPAR19 Pioneira. A temperatura de cocção foi fator importante no grau de gelatinização, atingindo 89,9\% de gelatinização com $8,7 \%$ de hidratação a $80^{\circ} \mathrm{C}$ e $97,9 \%$ de gelatinização com 15,6\% de hidratação em água em ebulição para amostras de 12 meses da Catarina Amarela. Os tempos de cocção para atingir o maior grau de gelatinização possivel a $80^{\circ} \mathrm{C}$ foram mais longos para a cultivar Catarina Amarela que para a cultivar IAPAR-19 Pioneira, resultando em maior grau de gelatinização, 89,9\% em 152min para amido em tecidos de Catarina Amarela e $85,3 \%$ em 92min para amido em tecidos de IAPAR-19 Pioneira, aos 12 meses. Catarina Amarela cozinhou em 28min em água em ebulição enquanto IAPAR-19 Pioneira cozinhou em 12min, para amostras com 12 meses de plantio. CEREDA et al. [6] relataram 13,5min para tempo de cozimento para IAPAR-19 Pioneira aos 12 meses. 
Gelatinização e hidratação foram aparentemente completas em água em ebulição, mas sempre menores no tempo final de cocção para Catarina Amarela comparado com IAPAR-19 Pioneira e para amostras de 25 meses comparadas às de 12 meses. À temperatura da água em ebulição, comum para processamento doméstico, IAPAR-19 Pioneira cozinhou em 32min aos 25 meses, enquanto Catarina Amarela cozinhou em 56min. CEREDA et al. [6] descrevem 19,5min como tempo de cocção para a cultivar IAPAR-19 Pioneira aos 25 meses. Conforme a tabela de tempo de cozimento de PEREIRA, LORENZI \& VALLE [12] tempos de cozimento superiores a 30min são excessivos e as raízes não teriam qualidade suficiente para consumo.

TABELA 2. Hidratação e gelatinização durante a cocção de amostras de mandioca IAPAR-19 Pioneira.

\begin{tabular}{|c|c|c|c|c|c|c|c|c|c|c|c|}
\hline \multicolumn{6}{|c|}{ Cocção a $80^{\circ} \mathrm{C}$} & \multicolumn{6}{|c|}{ Temperatura da água em ebulição } \\
\hline \multicolumn{3}{|c|}{12 meses } & \multicolumn{3}{|c|}{25 meses } & \multicolumn{3}{|c|}{12 meses } & \multicolumn{3}{|c|}{25 meses } \\
\hline $\begin{array}{l}\text { Tempo } \\
\text { (minuto) }\end{array}$ & $\begin{array}{l}\text { Hidra- } \\
\text { tação } \\
(\%)\end{array}$ & $\begin{array}{c}\text { Gelatini- } \\
\text { zação } \\
(\%)\end{array}$ & $\begin{array}{l}\text { Tempo } \\
\text { (minuto) }\end{array}$ & $\begin{array}{c}\text { Hidra- } \\
\text { tação } \\
(\%)\end{array}$ & $\begin{array}{c}\text { Gelatini- } \\
\text { zação } \\
(\%)\end{array}$ & $\begin{array}{l}\text { Tempo } \\
\text { (minuto) }\end{array}$ & $\begin{array}{l}\text { Hidra- } \\
\text { tação } \\
(\%)\end{array}$ & $\begin{array}{c}\text { Gelatini- } \\
\text { zação } \\
(\%)\end{array}$ & $\begin{array}{l}\text { Tempo } \\
\text { (minuto) }\end{array}$ & $\begin{array}{c}\text { Hidra- } \\
\text { tação } \\
(\%)\end{array}$ & $\begin{array}{c}\text { Gelatini- } \\
\text { zação } \\
\text { (\%) }\end{array}$ \\
\hline 11,5 & 3,2 & 43,4 & 20 & 2,1 & 42,4 & 1,5 & 5,1 & 57,8 & 4 & 2,8 & 53,0 \\
\hline 23 & 5,5 & & 40 & 3,9 & & 3 & 7,0 & & 8 & 7,6 & \\
\hline 34,5 & 8,4 & & 60 & 6,8 & & 4,5 & 9,5 & & 12 & 11,8 & \\
\hline 46 & 13,4 & 67,4 & 80 & 10,9 & 60,2 & 6 & 12,5 & 85,1 & 16 & 13,0 & 79,7 \\
\hline 57,5 & 17,4 & & 100 & 13,7 & & 7,5 & 16,2 & & 20 & 17,0 & \\
\hline 69 & 19,4 & & 120 & 17,4 & & 9 & 24,0 & & 24 & 20,1 & \\
\hline 80,5 & 22,1 & 84,1 & 140 & 19,0 & 73,1 & 10,5 & 28,1 & 94,6 & 28 & 22,4 & 95,0 \\
\hline 92 & 25,4 & 85,3 & 160 & 21,0 & 74,7 & 12 & 33,2 & 98,0 & 32 & 25,5 & 97,5 \\
\hline Média & $14,2 \pm 7$, & & & $11,8 \pm 7$ & & & $6,9 \pm 10$ & & & $15,0 \pm 7$ & \\
\hline
\end{tabular}

TABELA 3. Hidratação e gelatinização durante a cocção de amostras de mandioca Catarina Amarela.

\begin{tabular}{|c|c|c|c|c|c|c|c|c|c|c|c|}
\hline \multicolumn{6}{|c|}{ Cocção a $80^{\circ} \mathrm{C}$} & \multicolumn{6}{|c|}{ Temperatura da água em ebulição } \\
\hline \multicolumn{3}{|c|}{12 meses } & \multicolumn{3}{|c|}{25 meses } & \multicolumn{3}{|c|}{12 meses } & \multicolumn{3}{|c|}{25 meses } \\
\hline $\begin{array}{l}\text { Tempo } \\
\text { (minuto) }\end{array}$ & $\begin{array}{c}\text { Hidra- } \\
\text { taçăo } \\
(\%)\end{array}$ & $\begin{array}{c}\text { Gelatini- } \\
\text { zaçăo } \\
(\%)\end{array}$ & $\begin{array}{l}\text { Tempo } \\
\text { (minuto) }\end{array}$ & $\begin{array}{l}\text { Hidra- } \\
\text { taçăo } \\
(\%)\end{array}$ & $\begin{array}{c}\text { Gelatini- } \\
\text { zaçăo } \\
(\%)\end{array}$ & $\begin{array}{l}\text { Tempo } \\
\text { (minuto) }\end{array}$ & $\begin{array}{l}\text { Hidra- } \\
\text { taçăo } \\
(\%)\end{array}$ & $\begin{array}{c}\text { Gelatini- } \\
\text { zaçăo } \\
(\%)\end{array}$ & $\begin{array}{l}\text { Tempo } \\
\text { (minuto) }\end{array}$ & $\begin{array}{l}\text { Hidra- } \\
\text { taçăo } \\
(\%)\end{array}$ & $\begin{array}{c}\text { Gelatini- } \\
\text { zaçăo } \\
\text { (\%) }\end{array}$ \\
\hline 19 & 1,7 & 52,2 & 35 & 1,2 & 40,7 & 3,5 & 1,4 & 65,1 & 7 & 1,3 & 53,7 \\
\hline 38 & 1,9 & & 70 & 1,5 & & 7 & 2,1 & & 14 & 1,8 & \\
\hline 57 & 2,6 & & 105 & 2,5 & & 10,5 & 2,4 & & 21 & 3,0 & \\
\hline 76 & 3,6 & 72,8 & 140 & 3,7 & 62,3 & 14 & 6,2 & 82,7 & 28 & 3,9 & 79,7 \\
\hline 95 & 4,1 & & 175 & 4,7 & & 17,5 & 8,0 & & 35 & 4,3 & \\
\hline 114 & 5,2 & & 210 & 5,3 & & 21 & 11,0 & & 42 & 5,3 & \\
\hline 133 & 7,3 & 88,5 & 245 & 6,4 & 76,9 & 24,5 & 14,3 & 95,9 & 49 & 7,2 & 96,6 \\
\hline 152 & 8,7 & 89,9 & 280 & 6,6 & 78,9 & 28 & 15,6 & 97,9 & 56 & 9,1 & 97,5 \\
\hline
\end{tabular}

\section{3 - Modelos para a hidratação em diferentes tem- peraturas}

A hidratação durante a cocção a $80^{\circ} \mathrm{C}$ e em água em ebulição, das duas cultivares e nas duas épocas de colheita, foi representada por modelo matemático de ordem zero $\mathrm{y}=\mathrm{a}+\mathrm{bx}$, onde $\mathrm{y}=$ valor em $\%$ de hidratação, $\mathrm{a}=$ hidratação no tempo zero, $\mathrm{b}=$ constante de velocidade em \% de hidratação/min e x= tempo de cocção em minutos (Figuras 1 e 2).

Os modelos para hidratação, em água em ebulição, tiveram constantes de velocidades que variaram entre 2,77\%/min de cocção para a IAPAR-19 Pioneira aos 12 meses, o maior ganho de peso e menor tempo de cocção e $0,15 \% / \mathrm{min}$ para a Catarina Amarela de 25 meses, o menor ganho de peso e o maior tempo de cocção. Os coeficientes de determinação próximos a 1 mostram que a modelagem foi adequada e que o grau de hidratação pode ser estimado. Diferente da hidratação a gelatinização do amido é geralmente descrita por modelos de primeira ordem $[4,8]$. Comparando-se os valores no final do processo de cocção é possivel detectar que os incrementos no grau de gelatinização diminuíram a cada intervalo de tempo enquanto a hidratação continuou com incrementos lineares.

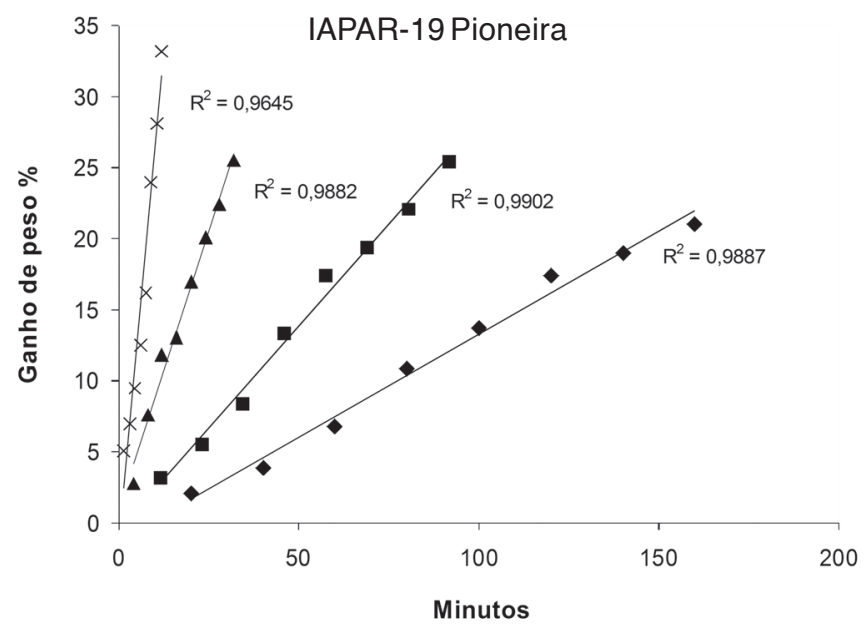

FIGURA 1. Modelagem da hidratação durante a cocção. Temperatura de $98^{\circ} \mathrm{C}$, tecidos de 12 meses (X) e 25 meses $(\boldsymbol{\nabla})$. Temperatura $80^{\circ} \mathrm{C}$, tecidos de 12 meses $(\boldsymbol{\nabla})$ e 25 meses $(\diamond)$.

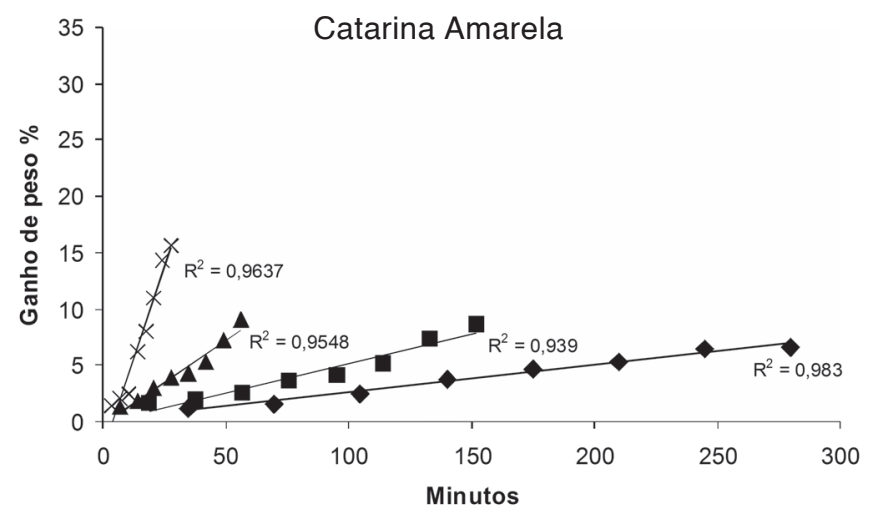

FIGURA 2. Modelagem da hidratação durante a cocção. Temperatura de $98^{\circ} \mathrm{C}$, tecidos de 12 meses (X) e 25 meses $(\boldsymbol{\nabla})$. Temperatura $80^{\circ} \mathrm{C}$, tecidos de 12 meses (घ) e 25 meses $(\diamond)$.

\section{4 - CONCLUSÕES}

A $80^{\circ} \mathrm{C}$, temperatura superior a de gelatinização de amido isolado de mandioca, não houve 100\% de gelati- 
nização do amido contido nas células dos tecidos das raízes, independente do tempo de cozimento. À temperatura da água em ebulição, a gelatinização do amido contido nos tecidos foi completa, mas as raízes processadas em diferentes idades e épocas de colheita necessitaram de tempos diferentes de cocção. Graus iguais de hidratação não correspondem a mesmo grau de gelatinização. Quanto mais rápida a hidratação mais rápido o cozimento para as duas cultivares e maturidades e quanto maior a hidratação, maior o rendimento que será obtido na comercialização de produto pré-cozido.

\section{5 - REFERÊNCIAS BIBLIOGRÁFICAS}

[1] AMERICAN ASSOCIATION OF CEREAL CHEMISTS Approved methods of the American Association of Cereal Chemists. 7 ed. Saint Paul: AACC, 1995 2v.

[2] BILIADERIS, C.G. Structures and phase transitions of starches in food systems. Food Technol., v. 45, n. 6 , p. 98-109,145, 1992.

[3] BIRCH, G.G.; PRIESTLEY, R.J. Degree of starch gelatinization of cooked rice. Die Starch, v. 25 p. 98100, 1973.

[4] CAI, W.; DIOSADY, L.L. Model for gelatinization of wheat starch in a twin-screw extruder. J. Food Sci., v. 68, p. 873-876, 1993.

[5] CARVAlHO, P.C.L.; FUKUDA, W.M.G.; CRUZ, P.J.; COSTA, J.A. Avaliação agronômica e tecnológica de cultivares de mandioca para consumo "in natura" Rev. Bras. Mand. v. 14, n. 1/2, p. 7-15, 1995.

[6] CEREDA, M.P.; SARMENTO, S.B.S.; WOSIACKI, G.; ABBUD, N.S.A mandioca (Manihot esculenta, C.) cultivar IAPAR-19 Pioneira 3- Características culinárias. Arq. Biol. Tecnol., v. 33, n. 3, p. 511-525, 1990.

[7] EGGLESTON, G.; ASIEDU, R. Effects of boiling on the texture of cassava clones: a comparison of compressive strength, intercellular adhesion and physicochemical composition of the tuberous roots. Trop. Sci., v. 34, p. 259-273, 1994.
[8] HARADA, T.; TIRTOHUSODO, H.; PAULUS, K. Influence of temperature and time on cooking kinetics of potatoes. J. Food Sci., v. 50, p. 459-462, 1985.

[9] HARADA, T.; TIRTOHUSODO, H.; PAULUS, K. Influence of the composition of potatoes on their cooking kinetics. J. Food Sci., v. 50, p. 463-468, 1985.

[10] LANARA Métodos analíticos oficiais para controle de produtos de origem animal e seus ingredientes. Brasília: Ministério da Agricultura, 1981, v. 1, Métodos Físicos e Químicos.

[11] LORENZI, J.O. Variação na qualidade culinária das raízes de mandioca. Bragantia, v. 53, n. 2, p. 237-245, 1994.

[12] PEREIRA, A.S.; LORENZI, J.O.; VALLE, T.L. Avaliação do tempo de cozimento e padrão de massa cozida em mandioca de mesa. R. Bras. Mand., v. 4, n. 1, p. 27-32, 1985.

[13] SAFO-KANTANKA, O.; OWUSU-NIPAH, J. Cassava varietal screening for cooking quality: relationship between dry matter, starch content, mealiness and certain microscopic observations of the raw and cooked tuber. J. Sci. Food Agric., v. 60, p. 99-104, 1992.

[14] SAS INSTITUTE INC. SAS User's guide: Statistics, version 5 edition. Cary, NC: SAS Institute, 1985.

[15] SNEDECOR, G.W.; COCHRAN, W.G. Statistical Methods. The Iowa State University Press, Ames. Cap.14: Analysis of Covariance. p. 419-443, 1967.

[16] WOSIACKI, G.; CEREDA, M.P.; SARMENTO, S.B.S.; ABBUD, N.S. A mandioca (Manihot esculenta, C.) cultivar IAPAR-19 Pioneira 2- Características da fração amido. Arq. Biol. Tecnol., v. 33, n. 2, p. 255-264, 1990.

\section{6 - AGRADECIMENTOS}

Ao Conselho Nacional de Desenvolvimento Científico e Tecnológico-CNPq pelas bolsas dos autores Butarelo, Ito e Beléia. À Dra. Lílian Azevedo Miranda pelo fornecimento da matéria-prima. 